\title{
EFEITO DO pH DO SOLO RIZOSFÉRICO E NÃO RIZOSFÉRICO DE PLANTAS DE SOJA INOCULADAS COM Bradyrhizobium japonicum NA ABSORÇÃO DE BORO, COBRE, FERRO, MANGANÊS E ZINCO(1)
}

\author{
Luiz Humberto Souza ${ }^{(2)}$, Roberto Ferreira Novais ${ }^{(3)}$, Víctor Hugo \\ Alvarez V. ${ }^{(3)}$ \& Ecila Mercês de Albuquerque Villani ${ }^{(4)}$
}

\begin{abstract}
RESUMO
Alterações no $\mathrm{pH}$ da rizosfera de plantas fixadoras de $\mathrm{N}_{2}$ parecem exercer papel fundamental na absorção de micronutrientes que têm sua disponibilidade dependente de alterações da acidez do solo. Estudaram-se variações na absorção de $\mathrm{B}, \mathrm{Cu}, \mathrm{Fe}, \mathrm{Mn}$ e $\mathrm{Zn}$ durante o ciclo de crescimento e desenvolvimento da soja, induzidas pela fixação biológica de $\mathrm{N}_{2}$ e pelo $\mathrm{pH}$ inicial de amostras de dois solos (um LV argiloso e outro arenoso), em um ensaio conduzido em casa de vegetação. Essas amostras foram incubadas com doses de $\mathrm{CaCO}_{3}+\mathrm{MgCO}_{3}(4: 1)$ para elevar o pH $\left(\mathrm{H}_{2} \mathrm{O}\right)$ a valores de 5,2, 5,6, 6,2 e 6,6 no solo argiloso e 5,3, 5,6, 5,9 e 6,3 no solo arenoso. Após 60 dias de incubação, essas amostras receberam $450 \mathrm{mg} \mathrm{dm}^{-3} \mathrm{de} \mathrm{P} \mathrm{e}$ $120 \mathrm{mg} \mathrm{dm}^{-3}$ de K no solo. Sementes de soja (Glycine max (L) Merrill), variedade Paranaíba, inoculadas com Bradyrhizobium japonicum, estirpes SEMIA 587 e SEMIA 5019, foram colocadas para germinar. Foram cultivadas quatro plantas por vaso $\left(2,2 \mathrm{dm}^{3}\right)$ e colhidas aos $16,20,24,28,32,36,40,46$ e 54 dias após a emergência. Determinaram-se o $\mathrm{pH}$ da rizosfera $\left(\mathrm{pH}_{\mathrm{r}}\right)$, o $\mathrm{pH}$ do solo entre raízes não rizosférico $\left(\mathrm{pH}_{\mathrm{nr}}\right)$, os teores de $\mathrm{B}, \mathrm{Cu}, \mathrm{Fe}, \mathrm{Mn}$ e de $\mathrm{Zn}$ na parte aérea e raiz, o $\mathrm{N}$ apenas na parte aérea, o número de nódulos e o peso da matéria seca de parte aérea, raiz e nódulos. Observou-se que as mudanças ocorridas no $\mathrm{pH}_{\mathrm{r}}$ e $\mathrm{pH}_{\mathrm{nr}}$ foram dependentes do $\mathrm{pH}$ inicial dos solos $\left(\mathrm{pH}_{\mathrm{s}}\right)$ e da fixação biológica de $\mathrm{N}_{2}$. O acúmulo de $\mathrm{B}$ e de Fe na parte aérea não foi alterado pelos valores de $\mathrm{pH}_{\mathrm{r}}$, modificados em função do $\mathrm{pH}_{\mathrm{s}}$, exceto para o Fe no solo argiloso. Todavia, aumentos significativos no acúmulo destes nutrientes na parte aérea ocorreram com o aparecimento dos
\end{abstract}

\footnotetext{
(1) Parte da Tese de Doutorado do primeiro autor apresentada ao Departamento de Fitotecnia da Universidade Federal de Viçosa - UFV. Recebido para publicação em agosto de 2009 e aprovado em agosto de 2010.

(2) Professor do Departamento de Fitotecnia e Zootecnia da Universidade do Sudoeste da Bahia - UESB. Caixa Postal 95, CEP 45083-900 Vitória da Conquista (BA). E-mail: lh.luizhumberto@gmail.com

(3) Professor do Departamento de Solos da Universidade Federal de Viçosa - UFV. CEP 36570-000 Viçosa (MG). E-mails: rfnovais@ufv.br; vhav@ufv.br

(4) Engenheira-Agrônoma, Pós-Doutoranda em Solos e Nutrição de Plantas. Bolsista da FAPEMIG. E-mail: ecilavillani@yahoo.com.br
} 
nódulos, a partir de 24 dias após a emergência. Para $\mathrm{Cu}, \mathrm{Mn}$ e $\mathrm{Zn}$, as diferenças apareceram sobretudo quanto ao $\mathrm{pH}_{\mathrm{s}}$. $\mathrm{O}$ conteúdo de micronutrientes na planta revelou-se sensível a mudanças no $\mathrm{pH}$ rizosférico, principalmente após a nodulação.

Termos de indexação: acidez, fixação biológica, micronutrientes.

\author{
SUMMARY: EFFECTOF pHOF RHIZOSPHERICAND NON-RHIZOSPHERIC \\ SOIL ON BORON, COPPER, IRON, MANGANESE, AND ZINC \\ UPTAKE BY SOYBEAN PLANTS INOCULATED WITH \\ Bradyrhizobium japonicum
}

\begin{abstract}
Changes in the $\mathrm{pH}$ of the rhizosphere of $\mathrm{N}_{2}$-fixing plants seem to play a key role in the uptake of micronutrient whose availability depends on changes in soil acidity. Variations in the $\mathrm{B}, \mathrm{Cu}, \mathrm{Fe}, \mathrm{Mn}$, and $\mathrm{Zn}$ uptake were studied during soybean development and growth cycle under the influence of biological $N_{2}$ fixation and the initial $p H$ of two soils samples (a clayey and a sandy Yellow Latosol; Oxisols), in a greenhouse experiment. These samples were incubated with rates of $\mathrm{CaCO}_{3}+\mathrm{MgCO}_{3}$ (4:1) to raise the $\mathrm{pH}\left(\mathrm{H}_{2} \mathrm{O}\right)$ to 5.2, 5.6, 6.2, and 6.6 in the clay soil and to 5.3, 5.6, 5.9, and 6.3, respectively, in the sandy soil. After 60 days of incubation, the soil samples were fertilized with $450 \mathrm{mg} \mathrm{dm}^{-3} \mathrm{P}$ and $120 \mathrm{mg} \mathrm{dm}^{-3} \mathrm{~K}$. Soybean (Glycine max $(L)$ Merrill) seeds of the variety Paranaiba, inoculated with the strains SEMIA 587 and SEMIA 5019 of Bradyrhizobium japonicum were germinated. Four plants per pot $\left(2.2 \mathrm{dm}^{3}\right)$ were grown and harvested 16, 20,24, 28, 32, 36, 40, 46, and 54 days after emergence. The following variables were measured: $p H$ of the rhizosphere $\left(p H_{r}\right)$, the non-rhizospheric soil $p H$ (between roots) $\left(\mathrm{pH}_{n r}\right)$, the $\mathrm{B}, \mathrm{Cu}, \mathrm{Fe}, \mathrm{Mn}$ and $\mathrm{Zn}$ contents in shoots and roots, $N$ in the shoot, number of nodules, and the shoot, root and nodule dry matter. It was observed that changes in $p H_{r}$ and $\mathrm{pH}_{n r}$ depended on the initial soil $\mathrm{pH}\left(\mathrm{pH}_{s}\right)$ and on biological $\mathrm{N}_{2}$ fixation. The accumulation of $B$ and $F e$ in the shoots was not influenced by the $\mathrm{pH}_{r}$ values modified depending on the $\mathrm{pH}$, except for Fe in the clay soil. However, nodules appeared 24 days after emergence and nutrient accumulation was significantly increased from then on. For $\mathrm{Cu}, \mathrm{Mn}$ and $\mathrm{Zn}$ uptake seemed to be affected mainly by $\mathrm{pH}_{\mathrm{r}}$. The micronutrient content in the plants proved to be sensitive to changes in the rhizospheric $\mathrm{pH}$, particularly after nodulation.
\end{abstract}

Index terms: acidity, biological fixation, micronutrients.

\section{INTRODUÇÃO}

Nas últimas décadas, os micronutrientes passaram a despertar maior interesse dos técnicos e dos agricultores brasileiros. Paralelamente, surgiram estudos, em maior volume, sobre deficiência e toxidez causadas por esses nutrientes em diferentes culturas. De modo geral, essas deficiências estão associadas à calagem excessiva e ao consequente elevado valor do $\mathrm{pH}$ do solo e, em alguns casos, à pobreza do material de origem dos solos (Abreu et al., 2007). Alterações no $\mathrm{pH}$ de plantas fixadoras de $\mathrm{N}_{2}$ parecem exercer papel fundamental na absorção de micronutrientes que têm sua disponibilidade dependente de alterações do $\mathrm{pH}$ do solo, particularmente daquele da rizosfera.

Maiores mudanças no $\mathrm{pH}$ da rizosfera $\left(\mathrm{pH}_{\mathrm{r}}\right)$ são atribuídas à extrusão e absorção de $\mathrm{H}^{+}$ou de $\mathrm{HCO}_{3}{ }^{-}$, respiração da raiz, liberação de exsudatos de baixa massa molecular (ácidos orgânicos, açúcares, fenóis, etc.) e, especialmente, à relação entre a absorção de cátions e a de ânions (Hinsinger et al., 2003; Taiz \& Zeiger, 2004). Dada a variação espacial (área superficial do sistema radicular) e temporal (mudanças induzidas pelo sistema radicular) quanto aos nutrientes absorvidos pelas plantas, verifica-se que elas raramente absorvem quantidades equivalentes de cátions e ânions. Como as raízes devem manter equilíbrio eletroquímico com o meio (rizosfera) e constância no $\mathrm{pH}$ intracelular, esses desbalanços na absorção iônica devem ser compensados pela simultânea extrusão de $\mathrm{H}^{+}$, quando em situações de predomínio da absorção de cátions, ou de liberação de $\mathrm{OH}^{-}$ou $\mathrm{HCO}_{3}{ }^{-}$ou $\mathrm{RCOO}^{-}$, quando do predomínio de ânions absorvidos. A extensão desse processo varia entre espécies e com o status nutricional da planta (Römheld \& Marschner, 1984; Jungk, 1991).

Na prática, a alteração do $\mathrm{pH}$ rizosférico (relação $\mathrm{H}^{+} / \mathrm{HCO}_{3}{ }^{-}$) pode ser influenciada pela aplicação de fertilizantes, especialmente fontes de $\mathrm{N}$, se amoniacal $\left(\mathrm{N}-\mathrm{NH}_{4}{ }^{+}\right)$ou nítrica $\left(\mathrm{N}-\mathrm{NO}_{3}{ }^{-}\right)$. De acordo com Marschner \& Römheld (1983), a absorção de $\mathrm{N}_{-} \mathrm{NH}_{4}{ }^{+}$ promove o efluxo de $\mathrm{H}^{+}$, e a absorção de $\mathrm{N}_{-} \mathrm{NO}_{3}{ }^{-}$, de $\mathrm{HCO}_{3}{ }^{-}$. Entretanto, a proporção entre $\mathrm{N}-\mathrm{NO}_{3}{ }^{-}$e N$\mathrm{NH}_{4}{ }^{+}$absorvidos varia consideravelmente entre 
espécies e entre cultivares. Em plantas que fixam $\mathrm{N}_{2}$ simbioticamente, a origem principal do Né o molecular $\left(\mathrm{N}_{2}\right)$, causando desbalanço na proporção de cátions/ ânions $\left(\mathrm{N}-\mathrm{NO}_{3}{ }^{-}\right.$do solo, muito menos absorvido nessas condições), passando a planta a absorver mais cátions e a liberar $\mathrm{H}^{+}$predominantemente (Marschner, 1995).

Presume-se que a diferença no $\mathrm{pH}_{\mathrm{r}}$ entre espécies de plantas nutridas com $\mathrm{N}-\mathrm{NO}_{3}{ }^{-}$está relacionada com a capacidade de troca de cátions (CTC) do sistema radicular e, ou, de sítios de redução do $\mathrm{NO}_{3}{ }^{-}$. Com o aumento da CTC de raiz (dicotiledônea > monocotiledônea), a razão de absorção cátion/ânion é comumente alterada em favor de cátions e o $\mathrm{pH}_{\mathrm{r}}$ decresce (Hinsiger et al., 2003). Em leguminosas, a combinação de alta CTC com a fixação de $\mathrm{N}_{2}$ leva a um efetivo abaixamento do $\mathrm{pH}_{\mathrm{r}}$.

Em solos ácidos, o aumento do $\mathrm{pH}_{\mathrm{r}}$ e o consequente decréscimo na atividade do $\mathrm{Al}$ podem ser considerados mecanismos de adaptação de espécies de plantas e de variedades a condições adversas de acidez do solo. Aumentos de $\mathrm{pH}_{\mathrm{r}}$ podem apresentar efeitos benéficos ou maléficos no crescimento de plantas. Em solos alcalinos ou que receberam calagem, o aumento do $\mathrm{pH}$ pode levar à menor disponibilidade de micronutrientes, como Fe, Mn, Cu e Zn (Souza et al., 2007). Novais et al. (1989), em Latossolo VermelhoAmarelo com $\mathrm{pH}$ original de 6,7, relacionaram o aparecimento de sintomas de deficiência de Mn em plantas de soja com o alto $\mathrm{pH}$ do solo. Em solos ácidos, o aumento do $\mathrm{pH}_{\mathrm{r}}$ pode resultar em decréscimo da atividade do $\mathrm{Al}$ e, em alguns casos, também de $\mathrm{Mn}$, bem como no aumento da disponibilidade de alguns nutrientes (Silva \& Mendonça, 2007).

O objetivo deste trabalho foi estudar variações na absorção de B, Cu, Fe, Mn e Zn ao longo do ciclo inicial de crescimento de plantas de soja, como consequência de mudanças ocorridas no $\mathrm{pH}$ da rizosfera, induzidas pela fixação do $\mathrm{N}_{2}$ e pelo $\mathrm{pH}$ inicial do solo.

\section{MATERIAL E MÉTODOS}

Foram utilizadas amostras da camada superficial, de 0-20 cm, de um solo originário de Viçosa-MG (LV argiloso) e um de Três Marias-MG (LV arenoso), provenientes do Banco de Solos do Departamento de Solos da Universidade Federal de Viçosa - UFV (Quadro 1).

Foram adicionadas doses de $\mathrm{CaCO}_{3}+\mathrm{MgCO}_{3}(4: 1)$ correspondentes a 1,065, 2,085, 3,125 e $4,715 \mathrm{~g} \mathrm{dm}^{-3}$ ao solo argiloso e $0,0,0,144,0,469 \mathrm{e} 0,916 \mathrm{~g} \mathrm{dm}^{-3}$ ao solo arenoso, para obtenção de quatro níveis de $\mathrm{pH}$ nos solos, na faixa de valores entre 5,0 e 6,5. As doses necessárias para atingir os valores de $\mathrm{pH}$ foram obtidas por meio de curvas de incubação dos solos. Amostras de 5,0 $\mathrm{dm}^{3}$ de solos foram incubadas em sacos plásticos, por 60 dias, em casa de vegetação, com teor de umidade de 80 \% da capacidade de campo. Após
Quadro 1. Características químicas e físicas de amostras dos solos utilizados

\begin{tabular}{|c|c|c|}
\hline Característica & $\begin{array}{l}\text { Solo Argiloso } \\
\text { Viçosa (LV) }\end{array}$ & $\begin{array}{c}\text { Solo Arenoso } \\
\text { Três Marias (LVa) }\end{array}$ \\
\hline $\mathrm{pH} \mathrm{H} \mathrm{H}_{2} \mathrm{O}(1: 2,5)$ & 4,1 & 5,3 \\
\hline $\mathrm{P}\left(\mathrm{mg} \mathrm{dm}^{-3}\right)^{(1)}$ & 0,1 & 0,8 \\
\hline $\left.\mathrm{K}(\mathrm{mg} \mathrm{dm})^{-3}\right)^{(1)}$ & 6,3 & 11,9 \\
\hline $\mathrm{Na}^{+}\left(\mathrm{cmol}_{\mathrm{c}} \mathrm{dm}^{-3}\right)^{(1)}$ & 0,07 & 0,09 \\
\hline $\mathrm{Al}^{3+}\left(\mathrm{cmol}_{\mathrm{c}} \mathrm{dm}^{-3}\right)^{(2)}$ & 0,55 & 0,26 \\
\hline $\mathrm{Ca}^{2+}\left(\mathrm{cmol}_{\mathrm{c}} \mathrm{dm}^{-3}\right)^{(2)}$ & 0,00 & 0,00 \\
\hline $\mathrm{Mg}^{2+}\left(\mathrm{cmol}_{\mathrm{c}} \mathrm{dm}^{-3}\right)^{(2)}$ & 0,00 & 0,00 \\
\hline $\mathrm{H}+\mathrm{Al}\left(\mathrm{cmol}_{\mathrm{c}} \mathrm{dm}^{-3}\right)^{(3)}$ & 4,50 & 2,40 \\
\hline $\mathrm{SB}\left(\mathrm{cmol}_{\mathrm{c}} \mathrm{dm}^{-3}\right)$ & 0,12 & 0,19 \\
\hline CTC efet. $\left(\mathrm{cmol}_{\mathrm{c}} \mathrm{dm}^{-3}\right)$ & 0,67 & 0,45 \\
\hline CTC $\mathrm{pH}_{7,0}\left(\mathrm{cmol}_{\mathrm{c}} \mathrm{dm}^{-3}\right)$ & 4,70 & 2,50 \\
\hline $\mathrm{V}(\%)$ & 12 & 7 \\
\hline m (\%) & 82 & 57 \\
\hline Areia grossa $\left(\mathrm{g} \mathrm{kg}^{-1}\right)$ & 150 & 530 \\
\hline Areia fina $\left(\mathrm{g} \mathrm{kg}^{-1}\right)$ & 80 & 310 \\
\hline Silte $\left(\mathrm{g} \mathrm{kg}^{-1}\right)$ & 70 & 20 \\
\hline Argila $\left(\mathrm{g} \mathrm{kg}^{-1}\right)$ & 700 & 140 \\
\hline
\end{tabular}

esse período, foram determinados os valores de $\mathrm{pH}$ em água, na relação 1:2,5, encontrando-se: $\mathrm{pH}_{1}=5,2$, $\mathrm{pH}_{2}=5,6, \mathrm{pH}_{3}=6,2$ e $\mathrm{pH}_{4}=6,6$ no solo argiloso e $\mathrm{pH}_{1}=5,3, \mathrm{pH}_{2}=5,6, \mathrm{pH}_{3}=5,9$ e $\mathrm{pH}_{4}=6,4$ no solo arenoso.

Antes de serem acondicionadas em vasos, sem furos, as amostras de $2,2 \mathrm{dm}^{3}$ receberam, em dose única, $450 \mathrm{mg} \mathrm{dm}^{-3} \mathrm{de} \mathrm{P}$ e $120 \mathrm{mg} \mathrm{dm}^{-3}$ de K de solo, nas formas superfostato simples e $\mathrm{KCl}$, respectivamente. Nitrogênio e micronutirentes não foram aplicados. Foram utilizadas sementes de soja [Glycine max (L) Merrill], variedade Paranaíba, provenientes do banco de germoplasma da UFV, passadas em peneira de $\mathrm{n}^{\circ} 15$ e retidas na de $\mathrm{n}^{\circ} 14$. Antes da semeadura, as sementes foram inoculadas com Bradyrhizobium japonicum, estirpes SEMIA 587 e SEMIA 5019, na proporção de $10 \mathrm{~g}$ do inoculante comercial para $0,5 \mathrm{~kg}$ de sementes com, aproximadamente, $10^{6}$ células viáveis por $\mathrm{mL}$. Foram colocadas para germinar 10 sementes por vaso, deixando-se quatro plantas após o desbaste. Nove coletas de plantas foram realizadas para as análises, aos $16,20,24,28,32,36,40,46$ e 54 dias após a emergência.

A umidade dos solos nos vasos foi mantida próxima a $80 \%$ da capacidade de campo, aplicando-se água destilada e pesando-se os vasos para recompor as diferenças.

O experimento foi conduzido em casa de vegetação, no período de agosto a outubro, com temperatura média mínima de $16{ }^{\circ} \mathrm{C}$ e máxima de $40^{\circ} \mathrm{C}$. Os tratamentos, constituídos de dois solos, quatro níveis de $\mathrm{pH}$ e nove coletas, no esquema fatorial $2 \times 4 \times 9$, foram dispostos segundo o delineamento experimental 
em blocos casualizados, com quatro repetições. Foram colhidos 32 vasos a cada coleta.

Em cada coleta, as plantas foram cortadas rente ao solo, separando-se a parte aérea, que foi lavada em água destilada, seca em estufa a $70^{\circ} \mathrm{C}$, por $72 \mathrm{~h}$, e posteriormente pesada e moída. $\mathrm{O}$ sistema radicular foi retirado dos vasos e separado do solo, para efetuar a determinação do $\mathrm{pH}$ rizosférico $\left(\mathrm{pH}_{\mathrm{r}}\right), \mathrm{pH}$ do solo entre raízes - $\mathrm{pH}$ não rizosférico $\left(\mathrm{pH}_{\mathrm{nr}}\right)$ e número de nódulos.

Para determinação do $\mathrm{pH}_{\mathrm{r}}, 10 \mathrm{~g}$ de raízes mais solo aderido foram agitados em água destilada, por $1 \mathrm{~h}$, na relação 1:2,5 (solo:água), e o pH, determinado após 30 min, conforme Luisi et al. (1983). Quanto à determinação do $\mathrm{pH}_{\mathrm{nr}}$, foram retiradas amostras de solo na altura do terço médio do vaso com plantas, procedendo-se à agitação em água destilada, por $1 \mathrm{~h}$, na relação 1:2,5, efetuando-se a leitura do pH após $30 \mathrm{~min}$.

A determinação dos teores de $\mathrm{Cu}, \mathrm{Fe}, \mathrm{Mn}$ e $\mathrm{Zn}$ foi feita nos extratos obtidos da digestão nítrico-perclórica da parte aérea e do sistema radicular, por espectrofotometria de absorção atômica (Gallo et al., 1971). Antes da secagem das raízes, elas foram lavadas em água corrente, deixadas submersas em solução de $\mathrm{NaOH} 0,01 \mathrm{~mol} \mathrm{~L}^{-1}$ por $1 \mathrm{~min}$, para permitir melhor retirada do solo, e passadas em água corrente e duas vezes em água destilada. Na extração do B, a digestão foi por via seca e a determinação pelo método da azometina-H (Wolf, 1989). O N total da parte aérea foi determinado pelo método microKjeldahl (Concon \& Soltess, 1973). Foi feita a contagem do número de nódulos e quantificação do peso de nódulos secos.

Os dados foram submetidos à análise de variância, e as médias, comparadas pelo teste de Tukey a $5 \%$.

\section{RESULTADOS E DISCUSSÃO}

\section{Valores de pH da rizosfera e do solo entre as raízes}

$\mathrm{O} \mathrm{pH}$ inicial do solo $\left(\mathrm{pH}_{\mathrm{s}}\right)$ alterou de forma acentuada o $\mathrm{pH}$ rizosférico $\left(\mathrm{pH}_{\mathrm{r}}\right)$ em ambos os solos, com valores variando de 4,7 a 6,3, no solo argiloso, e de 4,7 a 5,6, no arenoso (Figura 1). Observou-se tendência de estabilidade do $\mathrm{pH}_{\mathrm{r}}$ até 36 dias após a emergência, aproximadamente, e queda a partir daí, até o final do experimento.
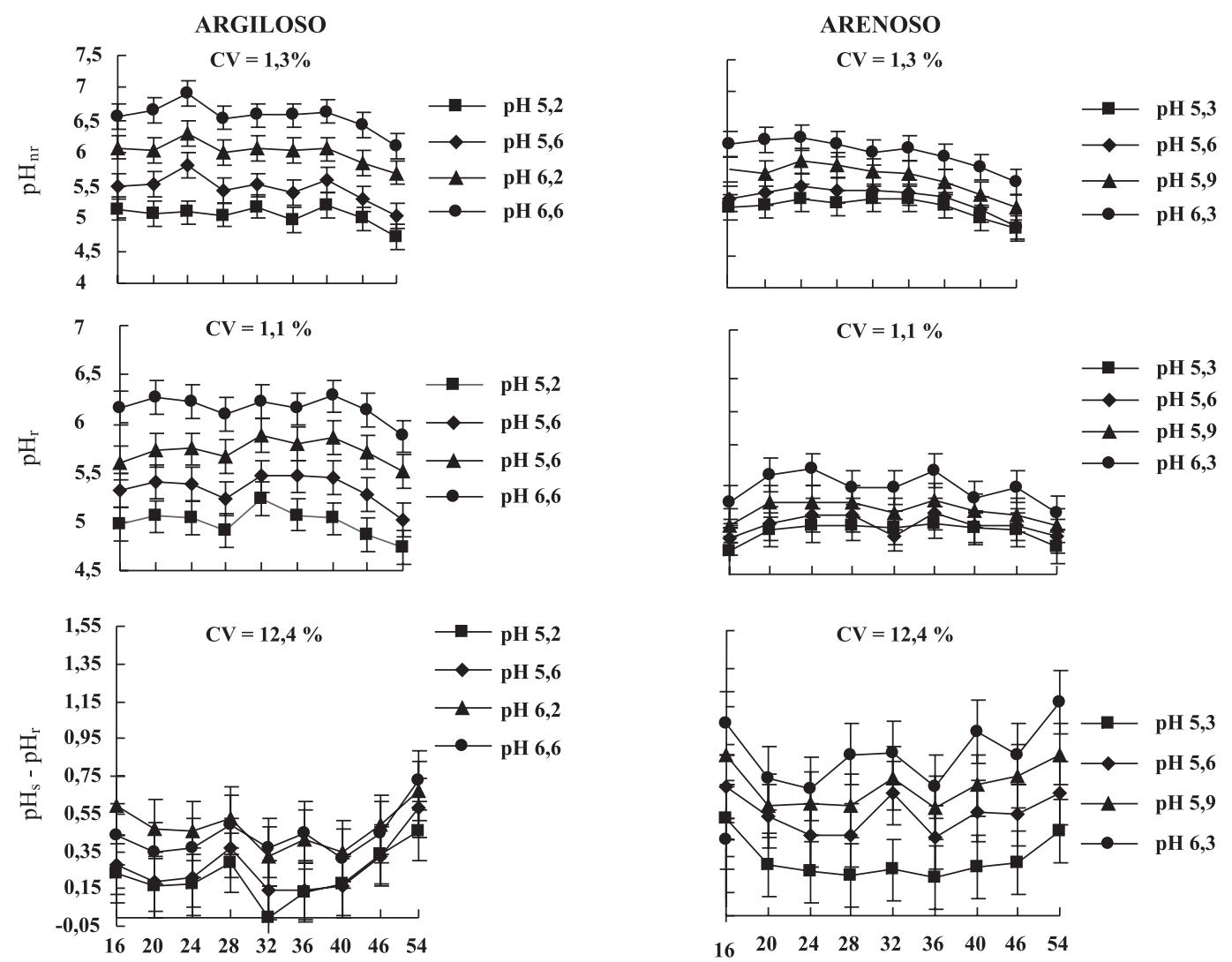

APÓS EMERGÊNCIA, dia

Figura 1. Efeito do $\mathrm{pH}$ inicial do solo argiloso e solo arenoso no $\mathrm{pH}$ rizosférico $\left(\mathrm{pH}_{\mathrm{r}}\right)$, no $\mathrm{pH}$ do solo entre raízes - não rizosférico $\left(\mathrm{pH}_{\mathrm{nr}}\right)$ e no poder-tampão do $\mathrm{pH}\left(\Delta \mathrm{pH}=\mathrm{pH}_{\mathrm{s}}-\mathrm{pH}_{\mathrm{r}}\right)$ em diferentes épocas de amostragem após a emergência de plantas de soja. 
$\mathrm{O} \mathrm{pH}_{\mathrm{s}}$ de ambos os solos alterou de forma significativa e positiva $(\mathrm{p}<0,01)$ o $\mathrm{pH}$ do solo entre raízes $\left(\mathrm{pH}_{\mathrm{nr}}\right)$ (Figura 1$)$. Até os 24 dias após a emergência, o $\mathrm{pH}_{\mathrm{nr}}$ aumentou, de modo geral, com a idade da planta, e, aos 40 e 36 dias após a emergência, para os solos argiloso e arenoso, respectivamente, 0 processo de acidificação acelerou. A acidificação ocorrida 36 dias após a emergência é coincidente com o início da mudança de fase vegetativa para a reprodutiva na soja, fase de maior atividade dos nódulos e maior fixação biológica de $\mathrm{N}_{2}$. Coincidindo com a queda do $\mathrm{pH}_{\mathrm{r}}$, observou-se nesse período que maiores $\Delta \mathrm{pH}\left(\mathrm{pH}_{\mathrm{s}}-\mathrm{pH}_{\mathrm{r}}\right)$ ocorrem em altos valores de $\mathrm{pH}$, no solo argiloso (6,2 e 6,6) e no arenoso (6,3) (Figura 1). Schubert et al. (1990) afirmaram que o influxo de $\mathrm{H}^{+}$ não dependeu da maior absorção de cátions e sim da extrusão de prótons pela atividade da ATPase em solos com baixo $\mathrm{pH}$; e a acidificação ocorrida na rizosfera, causada pela extrusão de prótons, não deve ser considerada resultado da fixação biológica de $\mathrm{N}_{2}$ (Zaharieva \& Römheld, 1991; Rossum et al., 1994).

A extensão da acidificação depende da taxa de prótons liberados e de sua difusão no solo (Schaller, 1987). O poder-tampão da acidez dos solos influencia a difusão de $\mathrm{H}^{+}$; quanto maior esse tamponamento, menor sua difusão, gerando menores valores de $\Delta \mathrm{pH}$. Desse modo, foram encontradas maiores diferenças nos valores de 0,60 a 0,12 unidade de $\mathrm{pH}$ no solo argiloso (mais tamponado) e de 1,10 a 0,41 unidade de $\mathrm{pH}$ no solo arenoso (Figura 1c). Encontrou-se correlação positiva e significativa entre $\mathrm{pH}_{\mathrm{r}}$ e $\mathrm{pH}_{\mathrm{nr}}$, sendo observados coeficientes de correlação maiores no solo argiloso que no arenoso (Quadro 2).

\section{Produção de matéria seca da parte aérea e do sistema radicular}

A produção de matéria seca da parte aérea e do sistema radicular das plantas, durante o período de 54 dias, foi diferente entre solos, observando-se maior crescimento no solo argiloso (Figura 2). A dependência da produção de matéria seca da parte aérea aos valores de $\mathrm{pH}_{\mathrm{s}}$ foi maior após 36 dias da emergência. Após esse período, as diferenças na acumulação de matéria

Quadro 2. Coeficiente de correlação linear simples entre os valores de pH do solo não rizosférico $\left(\mathrm{pH}_{\mathrm{nr}}\right)$ e da rizosfera $\left(\mathrm{pH}_{\mathrm{r}}\right)$ de plantas de soja em dois solos

\begin{tabular}{ccccc}
\hline \multirow{2}{*}{ Solo Argiloso } & & \multicolumn{2}{c}{ Solo Arenoso } \\
\cline { 1 - 2 } \cline { 5 - 5 } pH inicial & Correlação & & pH inicial & Correlação \\
\hline 5,3 & $0,76^{* *}$ & & 5,2 & $0,66^{*}$ \\
5,6 & $0,76^{* *}$ & & 5,6 & $0,52^{\circ}$ \\
6,2 & $0,53^{\circ}$ & & 5,9 & $0,59^{*}$ \\
6,6 & $0,84^{* *}$ & & 6,3 & $0,68^{*}$ \\
\hline
\end{tabular}

seca tenderam a ampliar-se com a maior taxa de crescimento para as condições dos maiores valores de pH inicial: 6,6, no solo argiloso, e 6,3, no arenoso. Comportamento semelhante foi verificado para o sistema radicular, exceto no solo argiloso, que proporcionou o menor crescimento a $\mathrm{pH} 6,6$; no solo arenoso, maior crescimento radicular foi observado nos valores de pH 5,9 e 6,3 (Figura 2).

\section{Nitrogênio na parte aérea, número e matéria seca de nódulos}

O acúmulo de $\mathrm{N}$ na parte aérea da planta mostrou diferente comportamento entre os dois solos (Figura 3). No solo argiloso, verificou-se aumento desde o início das avaliações, com pequenas variações de $\mathrm{pH}$ entre 5,6 e 6,6 . No solo arenoso, houve dois períodos com diferentes tendências de comportamento de aumento do conteúdo de $\mathrm{N}$ : pequeno acréscimo desses conteúdos até 40 dias após a emergência, aproximadamente, e rápido incremento daí para frente até o final do experimento, com exceção dos valores de $\mathrm{pH}_{\mathrm{s}} 5,3 \mathrm{e}$ 5,6 .

O aparecimento de nódulos foi observado, visualmente, aos 24 dias após a emergência (Figura 2). Os valores de $\mathrm{pH}_{\mathrm{s}}$ influenciaram o número de nódulos. No solo arenoso, o pH inicial alterou o número de nódulos, principalmente aos 32 dias da emergência, observando-se maior número em $\mathrm{pH}$ mais elevado ( $\mathrm{pH} 6$,3). $\mathrm{O}$ solo argiloso, $\mathrm{a} \mathrm{pH}_{\mathrm{s}} 6,6$, apresentou pequeno aumento no número de nódulos, inferior ao dos demais tratamentos, devido, em parte, ao menor crescimento da raiz.

A produção da matéria seca de nódulos não diferiu entre solos, distinguindo-se duas etapas: a primeira até 32 dias, com pequeno aumento, e daí para frente com rápido ganho de peso. Contudo, a resposta ao $\mathrm{pH}$ inicial do solo, no fim do período de observação, mostrou que o maior incremento no peso de nódulo no solo argiloso foi encontrado nos valores de $\mathrm{pH} 5,2 \mathrm{e}$ 5,6 e, no solo arenoso, em condições menos ácidas: pH 5,9 e 6,3 (Figura 2).

Não se verificou, inicialmente, crescimento satisfatório das plantas, ficando todas com coloração amarelada, típica do baixo suprimento de $\mathrm{N}$, sobretudo no solo arenoso.

$\mathrm{O}$ teor de $\mathrm{N}$ decresceu rapidamente até 28 dias após a emergência, em razão do aparecimento tardio dos nódulos (Figura 3). No solo arenoso, no início do florescimento da soja (40 dias), nos valores de $\mathrm{pH}_{\mathrm{s}}$ 5,9 e 6,3 , a fixação simbiótica de $\mathrm{N}_{2}$ aumentou sua efetividade, observada pelo rápido aumento no teor de N na planta. Uma hipótese seria que a decomposição dos nódulos poderia ter contribuído, nessa fase de crescimento das plantas, para um rápido incremento de N, observado pela redução no número de nódulos (Figura 2). 

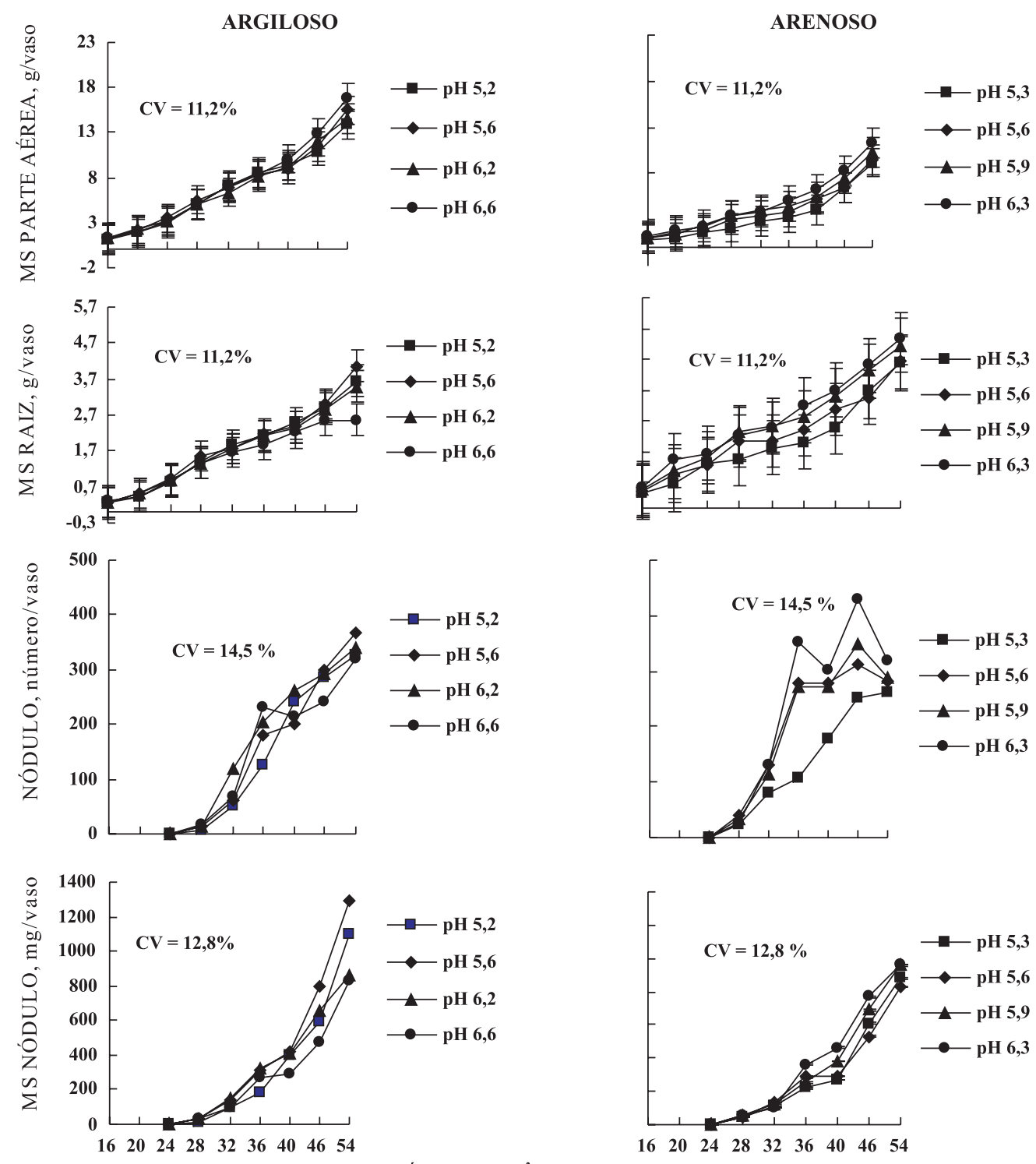

APÓS EMERGÊNCIA, dia

Figura 2. Produção de matéria seca da parte aérea, do sistema radicular e de nódulos e número de nódulos de plantas de soja, em diferentes épocas de avaliação após a emergência, em relação ao pH inicial do solo argiloso e do arenoso.

\section{Micronutrientes na parte aérea e nas raízes \\ Boro}

Os conteúdos de B na parte aérea e na raiz das plantas variaram entre os solos (Figura 4). As variações ocorridas nos conteúdos de B na parte aérea, em relação às mudanças no $\mathrm{pH}$ no solo argiloso e no arenoso, não foram significativas. $\mathrm{O}$ mesmo não ocorreu com o conteúdo de $\mathrm{B}$ na raiz $(\mathrm{p}<0,01)$. O conteúdo de $\mathrm{B}$ na parte aérea das plantas cultivadas no solo argiloso mostrou aumento praticamente constante durante o experimento, enquanto no solo arenoso, no período de 24 a 40 dias da emergência, manteve-se estável, aumentando daí para frente, coincidindo com o início de formação dos botões florais.
$\mathrm{O} \mathrm{pH}$ inicial dos solos não alterou o teor de $\mathrm{B}$ na parte aérea. Alguns autores mencionam que a biodisponibilidade do B é maior entre $\mathrm{pH}$ 5,5 e 7,5, decrescendo acima ou abaixo destes valores devido, principalmente, às reações $\mathrm{pH}$-dependentes (Mortvedt, 1999). Essa resposta pode estar associada com a baixa solubilidade do $\mathrm{B}(\mathrm{OH})_{4}{ }^{-}$a $\mathrm{pH}$ 7. Com o abaixamento do $\mathrm{pH}_{\mathrm{r}}$, o borato transforma-se em ácido bórico disponível para as plantas (Moraghan \& Mascagni Jr., 1991).

A soja é uma planta que apresenta pouca exigência a $\mathrm{B} \mathrm{e}$, assim, constitui-se em uma planta boa indicadora da toxidez causada por esse elemento (Jones Jr., 1991). $\mathrm{O}$ teor de B na matéria seca das plantas de soja, neste experimento, foi de 32 e $29 \mathrm{mg} \mathrm{kg}^{-1}$, respectivamente 

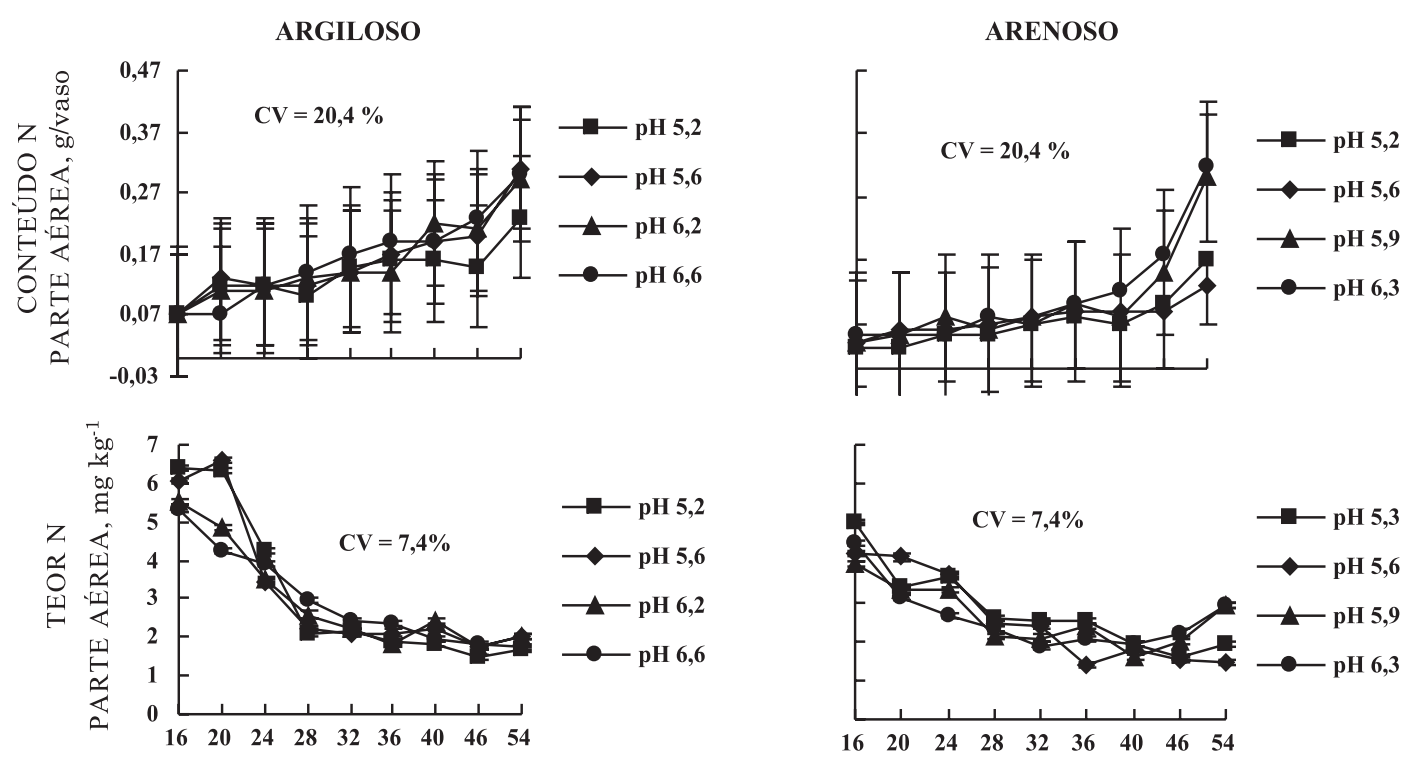

APÓS EMERGÊNCIA, dia

Figura 3. Conteúdo e teor de nitrogênio da matéria seca da parte aérea de plantas de soja, em diferentes épocas de avaliação após a emergência, em relação ao pH inicial do solo argiloso e do arenoso.
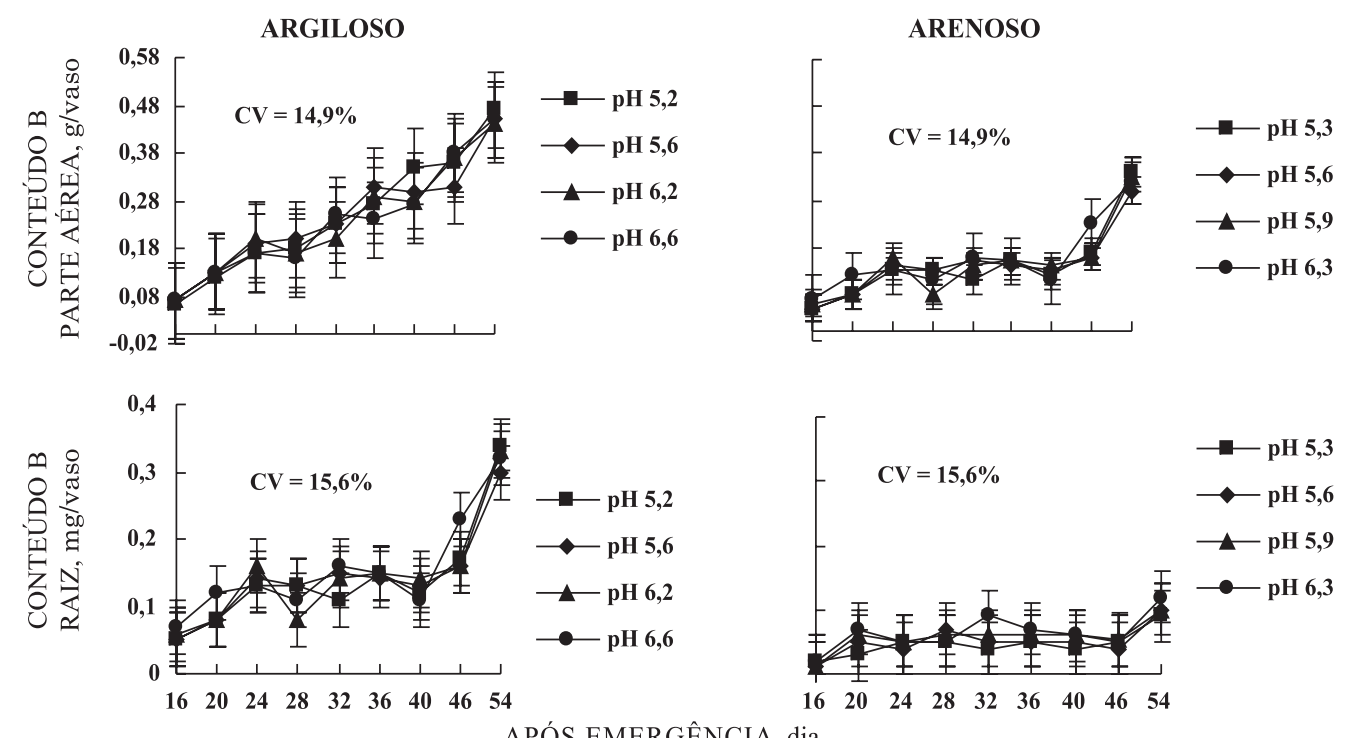

Figura 4. Conteúdo de boro da matéria seca da parte aérea e do sistema radicular de plantas de soja, em diferentes épocas de avaliação após a emergência, em relação ao pH inicial do solo argiloso e do arenoso.

no solo argiloso e no arenoso. Ambrosano et al. (1996) consideram ideal, para a soja, teor foliar de B entre 21 e $55 \mathrm{mg} \mathrm{kg}^{-1}$.

Nas raízes, foram verificados dois períodos de rápido incremento no conteúdo de B. O primeiro, entre 15 e 21 dias, como consequência do rápido crescimento radicular, e o segundo, aos 46 dias após a emergência, época de formação dos botões florais, período em que a planta intensifica a absorção de $\mathrm{N}$ e observa-se maior acidificação da rizosfera e do solo não rizosférico. Apesar de o B ser encontrado na solução do solo em forma de molécula não ionizada, $\mathrm{B}(\mathrm{OH})_{3}$, ele é móvel, sendo transportado principalmente por fluxo de massa (Moraghan \& Mascagni Jr., 1991).

\section{Cobre}

Neste trabalho, observou-se que o conteúdo de $\mathrm{Cu}$ na planta apresenta uma curva semelhante à do acúmulo de matéria seca da parte aérea (Figura 5). Jarvis (1981) relacionou o incremento na translocação de $\mathrm{Cu}$ para a parte aérea ao aumento no suprimento de $\mathrm{N}$, o que de fato ocorreu no solo arenoso nos valores 


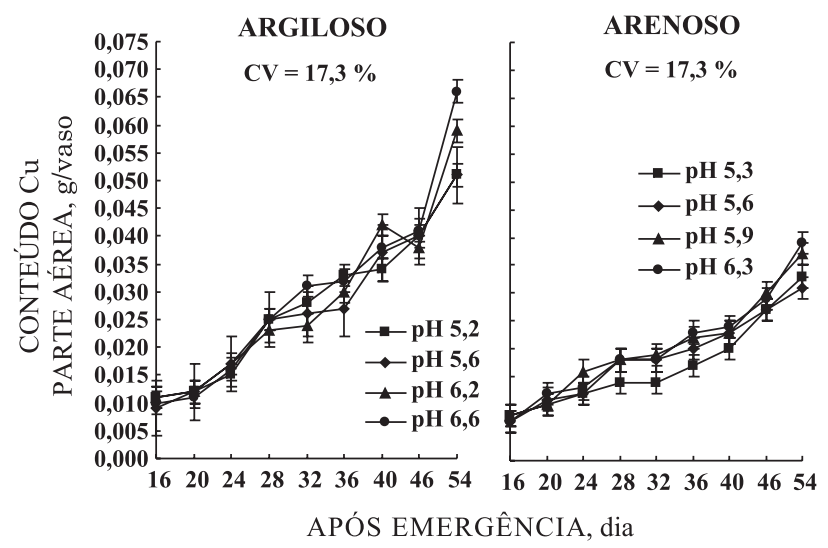

Figura 5. Conteúdo de cobre total da matéria seca da parte aérea de plantas de soja, em diferentes épocas de avaliação após a emergência, em relação ao pH inicial do solo argiloso e do arenoso.

de $\mathrm{pH} 5,9$ e 6,3, aos 40 dias da emergência. Para o solo argiloso, o rápido acúmulo verificado no $\mathrm{pH}_{\mathrm{s}} 6,6$, na última avaliação, pode estar relacionado com o rápido crescimento radicular. $\mathrm{O} \mathrm{Cu}$ tem afinidade com o átomo de $\mathrm{N}$ do grupo amino, e parece que compostos nitrogenados solúveis atuam como carregadores desse elemento no xilema e floema.

A adsorção de Cu eleva-se consideravelmente com o aumento do $\mathrm{pH}$ do solo de 4 para 7 (Cavallaro \& McBrige, 1984). Contudo, a absorção de $\mathrm{Cu}$ pelas plantas não é bem associada aos níveis menores de pH do solo. Essa baixa correlação pode ocorrer em solos onde existe predominantemente $\mathrm{Cu}$ ligado à matéria orgânica (quelatos) na fase sólida ou na solução do solo. Isso pode explicar por que em certos solos não ocorre deficiência desse elemento para as plantas com elevação do $\mathrm{pH}$, apesar de o $\mathrm{Cu}$ apresentar diminuição no seu fluxo difusivo com o aumento do pH (Pegoraro et al., 2006; Cornu et al., 2007).

\section{Ferro}

$\mathrm{O}$ menor $\mathrm{pH}$ favoreceu o acúmulo de Fe na matéria seca da parte aérea da planta no solo argiloso após 28 dias da semeadura (Figura 6). No solo arenoso houve incremento na absorção desse elemento somente a partir de 36 dias da emergência.

$\mathrm{O}$ acúmulo de $\mathrm{Fe}$ no sistema radicular apresentou comportamento distinto entre os solos estudados (Figura 6). No solo argiloso, não ocorreu efeito de $\mathrm{pH}_{\mathrm{s}}$ nos valores de 5,2 e 6,6, porém, com o crescimento da planta, observaram-se acréscimos significativos no conteúdo de Fe na raiz. No solo arenoso, o crescimento da raiz aos 54 dias da emergência não apresentou acúmulo significativo nos valores de 5,3 e 5,6, exceto nos valores de $\mathrm{pH}$ do solo de 5,9 e 6,3.

A absorção de Fe pelas plantas é metabolicamente controlada, podendo ser absorvido como $\mathrm{Fe}^{3+}, \mathrm{Fe}^{2+}$ ou Fe-quelato, precisando ser reduzido antes de entrar na célula. Portanto, parece fundamental a capacidade das raízes em reduzir $\mathrm{Fe}^{3+}$ para $\mathrm{Fe}^{2+}$ para que haja sua absorção (Robello et al., 2007). No espaço livre aparente, esse elemento pode estar presente na forma iônica ou de quelato. $\mathrm{O} \mathrm{Fe}$ na forma de quelato ou complexo orgânico fica protegido contra a insolubilização, porém a estabilidade do composto depende dos valores de $\mathrm{pH}$. Segundo Römheld \& Marschner (1983), o $\mathrm{Fe}^{3+}$ quelato é reduzido mais
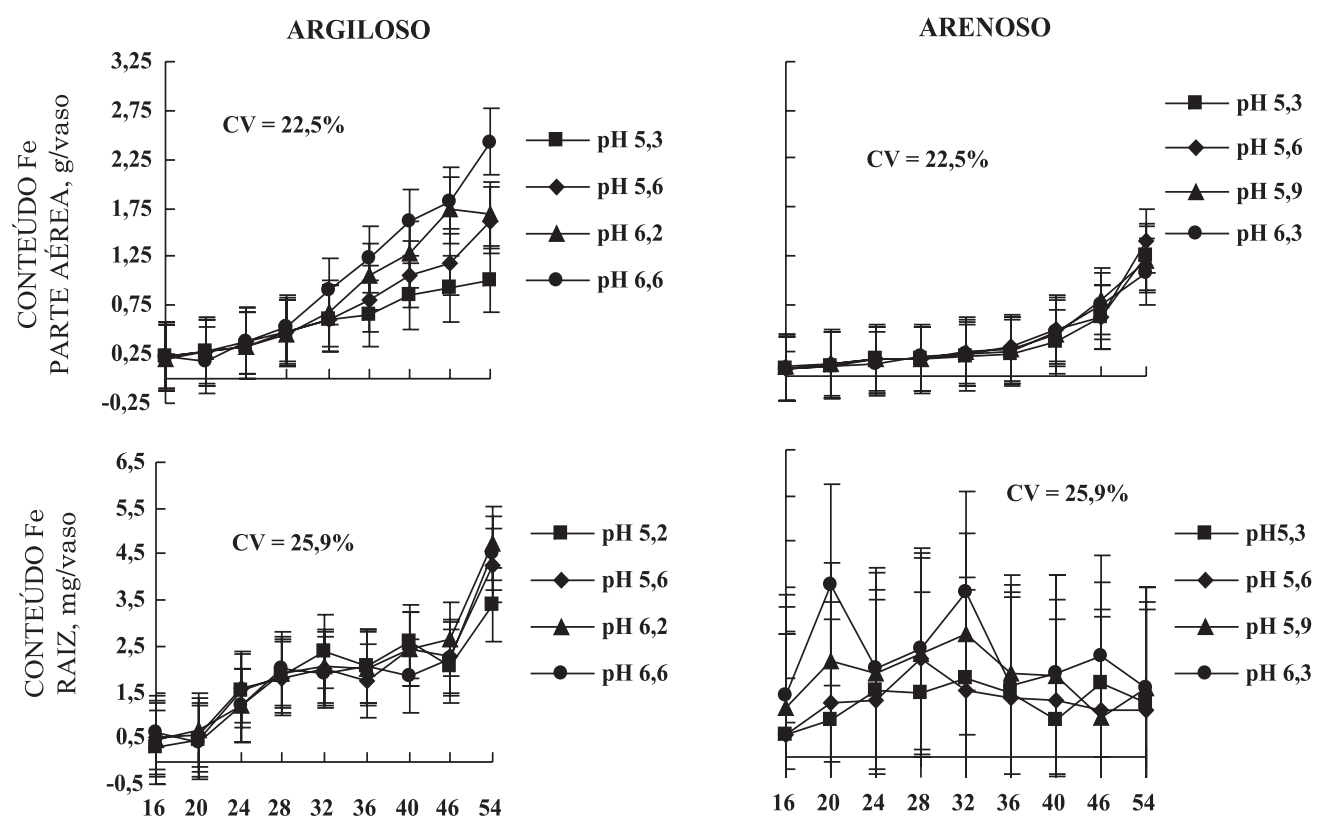

APÓS EMERGÊNCIA, dia

Figura 6. Conteúdo de ferro da matéria seca da parte aérea e do sistema radicular de plantas de soja, em diferentes épocas de avaliação após a emergência, em relação ao pH inicial do solo argiloso e do arenoso. 
rapidamente do que o $\mathrm{FeCl}_{3}$. A velocidade de redução do $\mathrm{Fe}$ depende do $\mathrm{pH}$ do meio e é maior em baixos valores de $\mathrm{pH}$. Dessa forma, a correção da acidez do solo para valores de $\mathrm{pH}$ em torno de 6,0 tende a restringir o efeito de aumento de disponibilidade de alguns micronutrientes (Cu e $\mathrm{Mn}$ ) sobre a absorção do Fe (Bataglia, 1991). A elevação do $\mathrm{pH}$ do solo interfere sobremaneira no fluxo difusivo desse elemento. Nunes et al. (2004) verificaram que o aumento do $\mathrm{pH}$ do solo por meio da calagem restringe fortemente o fluxo difusivo de Fe e pode até, juntamente com teores elevados de $\mathrm{P}$ disponíveis e de déficits hídricos, causar o aparecimento de sintomas de deficiência de Fe pela absorção insatisfatória deste por plantas de café.

As mudanças ocorridas no sistema radicular das plantas antes do aparecimento de nódulos não foram suficientes para aumentar o acúmulo de Fe na parte aérea, no solo argiloso, até 28 dias. A baixa nodulação ocorrida no solo arenoso fez com que a capacidade de fixação do $\mathrm{N}_{2}$ abaixar o $\mathrm{pH}$ fosse retardada, iniciandose aos 36 dias após a emergência, com consequente aumento no conteúdo de Fe na parte aérea. A soja pode demonstrar deficiência de $\mathrm{Fe}$ no início do crescimento, que desaparece à medida que a simbiose leguminosa com rizóbio se efetiva. Resultado semelhante foi observado por Wallace (1982), em soja, aos 35 dias da germinação.

Em muitas espécies de plantas, a indução da acidificação da rizosfera é importante mecanismo de mobilização do $\mathrm{Fe}^{3+}$. Se a taxa de extrusão de prótons não for uniformemente distribuída ao longo do sistema radicular, mas confinada a certas zonas das raízes, a eficiência dessas zonas pode ser alta em termos de absorção de Fe (Marschner \& Römheld, 1994).

\section{Manganês}

A absorção de Mn pela soja foi significativamente modificada pelo $\mathrm{pH}$ inicial dos solos (Figura 7). $\mathrm{O}$ seu conteúdo no sistema radicular não apresentou diferenças entre solos. As plantas cultivadas no solo arenoso mostraram tendência de aumento na absorção de $\mathrm{Mn}$, com maiores acúmulos na parte aérea e no sistema radicular, intensificada durante o início da floração (46 dias) da semeadura, coincidindo com queda constante do $\mathrm{pH}_{\mathrm{r}}$ e $\mathrm{pH}_{\mathrm{nr}}$ (Figura 1). No solo argiloso, nos valores de $\mathrm{pH}_{\mathrm{s}}$ de 6,2 e 6,6, o conteúdo total de Mn na matéria seca da parte aérea estabilizou-se quando a planta iniciou a floração. Em condições mais ácidas, $\mathrm{pH}_{\mathrm{s}} 5,2$ e 5,6, a absorção foi contínua e crescente.

Observaram-se acréscimos no conteúdo de Mn no sistema radicular no solo argiloso, principalmente em condições mais ácidas. Em valores de pH 6,2 e 6,6, os acréscimos foram menores e tenderam a estabilizar durante o crescimento. No solo arenoso, o conteúdo no sistema radicular até 20 dias após a emergência não diferiu entre os diversos valores de $\mathrm{pH}_{\mathrm{s}}$. Observouse a superioridade da condição de maior acidez em favorecer maior absorção de Mn após esse período, que foi maior nos valores de $\mathrm{pH}$ inicial do solo de 5,3 e 5,6. Nos valores de $\mathrm{pH}$ 5,9 e 6,3, ocorreu acréscimo moderado na absorção de Mn após o aparecimento dos nódulos e, também, no início do florescimento, em que o incremento na absorção de Mn foi dado pelo crescimento das raízes e maior volume de solo explorado. Apesar de o crescimento radicular ser importante para aumentar a absorção de $\mathrm{Mn}$, o processo de acidificação mostrou-se mais eficaz. No entanto, para o solo argiloso, a resposta à acidificação ocorrida nos valores de $\mathrm{pH}$ inicial do solo de 6,2 e 6,6, com valores de $\mathrm{pH}_{\mathrm{r}}$ de 5,5 a 5,8, aos 46 dias, foi pequena, devido ao maior poder-tampão conferido a esse solo e à menor fixação do $\mathrm{N}_{2}$.

A relação entre $\mathrm{pH}$ da rizosfera e absorção de $\mathrm{Mn}$ é muito complexa. No solo, o elemento encontra-se em amplo espectro de formas, porém é aceito como regra que decréscimo no $\mathrm{pH}$ rizosférico favorece a redução e aumenta a concentração de $\mathrm{Mn}^{2+}$, aumentando sua absorção pelas plantas. A adição de calcário em solos ácidos decresce a disponibilidade de Mn para a soja (Tanaka et al., 1990; Oliveira Jr. et al., 2000) e aumento na produção de matéria seca como resposta a doses de Mn no solo ocorre em níveis de $\mathrm{pH}$ acima de 6,8 (Oliveira et al., 1997). Comportamento diferencial entre cultivares, quanto à eficiência em absorver e, ou, utilizar Mn em condições de disponibilidade limitada no solo, tem sido observado. A variedade Paranaíba, segundo Oliveira et al. (1997), apresenta sintomatologia visual de deficiência de Mn, apesar de não se relacionar com a produção de matéria seca, a partir de pH 6,8. Novais et al. (1989) observaram sintoma de deficiência de Mn, nas folhas inferiores de plantas de soja, para $\mathrm{pH}$ acima de 6,5, em solo de textura média.

A quantidade de Mn solubilizado na rizosfera é muito maior que na solução do solo (Godo \& Reisenauer, 1980). Raízes de plantas sensíveis à deficiência de $\mathrm{Fe}$ podem levar ao aumento na mobilização de $\mathrm{Mn}^{2+}$ na rizosfera e estimular a absorção desse elemento (Marschner et al., 1982).

\section{Zinco}

O acúmulo de Zn na parte aérea das plantas variou com os valores do $\mathrm{pH}$ inicial dos solos. A absorção desse nutriente decresceu à medida que o $\mathrm{pH}$ do solo aumentou (Figura 8). O conteúdo de $\mathrm{Zn}$, sobretudo no sistema radicular, aumentou com o crescimento da planta, de modo mais intenso após 40 dias da emergência. Nesse período, o processo de acidificação da rizosfera proporcionado pela intensificação da fixação biológica do $\mathrm{N}_{2}$, no início da floração, tornouse mais ativo. De acordo com Bressan et al. (2006), os fungos micorrízicos têm maior importância na absorção de nutrientes de baixa difusão no solo, como $\mathrm{P}, \mathrm{Zn}$ e $\mathrm{Cu}$.

O efeito do $\mathrm{pH}$ inicial do solo sobre o conteúdo de Zn na parte aérea das plantas foi significativo apenas no solo argiloso. Maiores valores de $\mathrm{pH}$ proporcionaram 

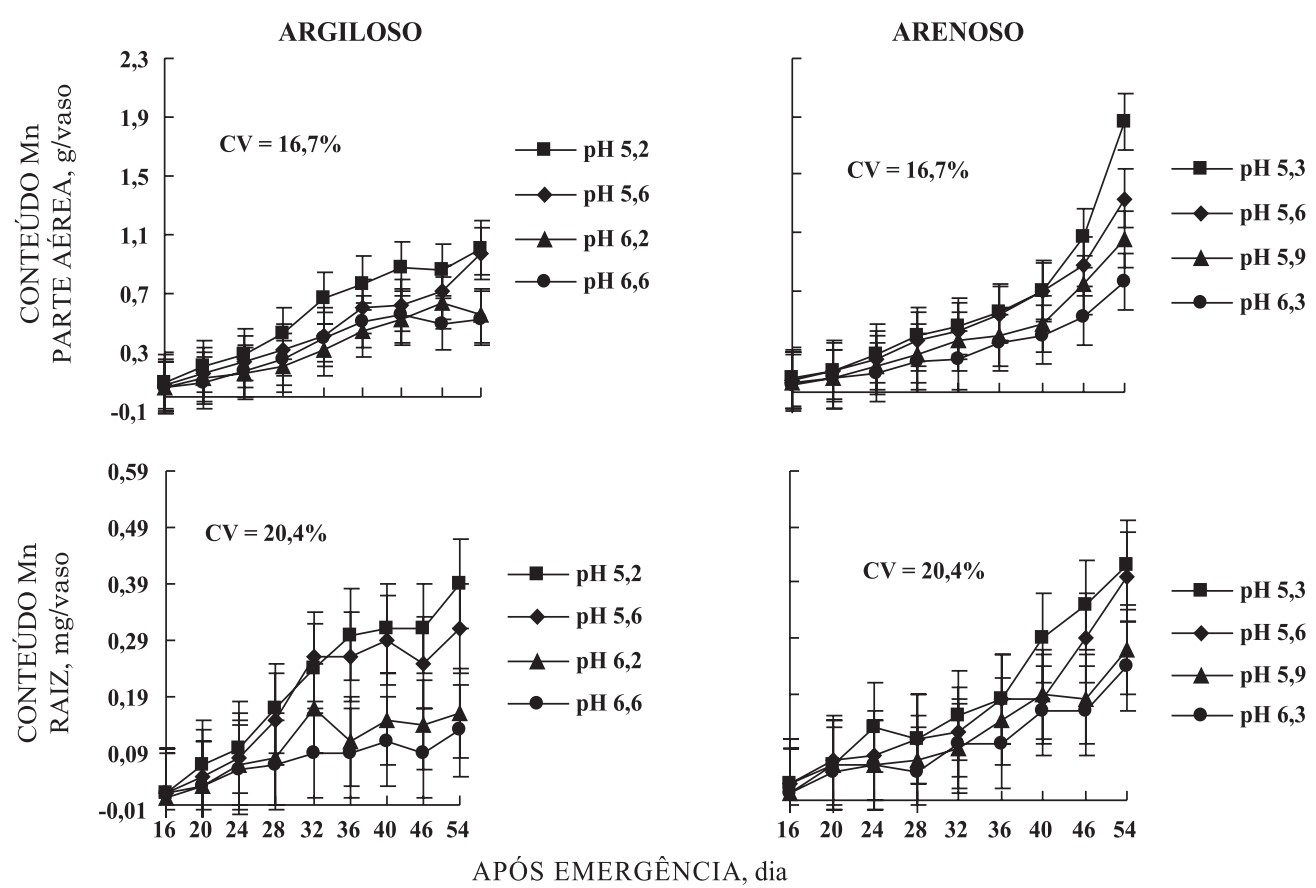

Figura 7. Conteúdo de manganês na matéria seca da parte aérea e do sistema radicular de plantas de soja, em diferentes épocas de avaliação após a emergência, em relação ao pH inicial do solo argiloso e do arenoso.
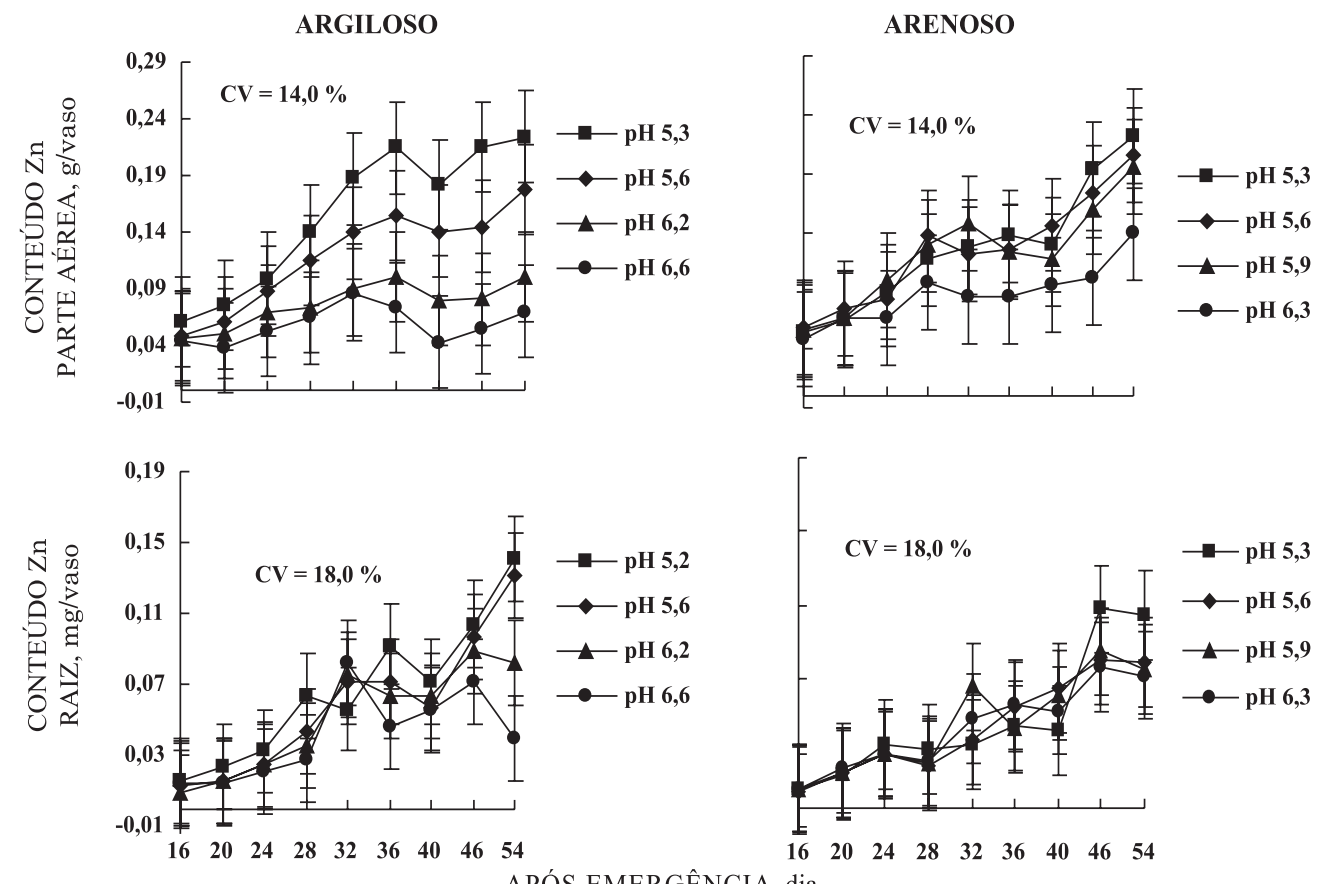

Figura 8. Conteúdo de zinco da matéria seca da parte aérea e do sistema radicular de plantas de soja, em diferentes épocas de avaliação após a emergência, em relação ao pH inicial do solo argiloso e do arenoso.

menores teores de Zn na parte aérea e nas raízes das plantas de soja, especialmente no solo arenoso. Tisdale et al. (1985) relacionaram, além do $\mathrm{pH}$ e de outros fatores alterando a disponibilidade e transporte do $\mathrm{Zn}$ no solo, a adsorção ou precipitação causada pelos carbonatos do solo. A adsorção do Zn é maior em carbonato de magnésio; em dolomita, apresenta grau intermediário; e em carbonato de cálcio, menor adsorção. O Zn ocupa o lugar do Mg na superfície do cristal ou, então, precipita na forma de hidróxido ou 
de carbonato de Zn. Neste trabalho, devido ao forte tamponamento do solo argiloso, adicionaram-se maiores quantidades de carbonato de cálcio e de magnésio para atingir valores de $\mathrm{pH}$ semelhantes aos do solo arenoso.

$\mathrm{O}$ transporte de $\mathrm{Zn}$ da solução do solo até a superfície das raízes ocorre principalmente por difusão (Moraghan \& Mascagni Jr., 1991). Oliveira et al. (1999) e Pegoraro et al. (2006) observaram grandes restrições ao fluxo difusivo de $\mathrm{Zn}$ após elevarem o pH do solo por meio da calagem. Segundo Bar-Yosef et al. (1980), o efluxo de $\mathrm{H}^{+}$na rizosfera de plantas é mais efetivo em aumentar a absorção de Zn que a liberação de agentes quelantes pelas raízes, o que foi verificado por Subramanian et al. (2009) ao avaliarem a absorção de Zn por milho micorrizado. Sarkar \& Wyn (1982) relacionaram modificações no $\mathrm{pH}$ da rizosfera induzidas por diferentes fontes de $\mathrm{N}$ com a absorção de $\mathrm{Zn}$ e de $\mathrm{Mn}$. Um decréscimo no $\mathrm{pH}_{\mathrm{r}}$ de 6,6 para 5,0 correlacionou-se com o incremento linear na concentração de Zn na planta. A diferença entre a absorção de Zn e a de Mn está relacionada, provavelmente, com o modo de aquisição na rizosfera: dessorção de cátions trocáveis $\left(\mathrm{Zn}^{2+}, \mathrm{Mn}^{2+}\right)$ e combinação entre dissoluções e redução $\left(\mathrm{Mn}^{4+} \rightarrow \mathrm{Mn}^{2+}\right)$ (Marschner, 1991).

\section{CONCLUSÕES}

1. As mudanças ocorridas no $\mathrm{pH}$ da rizosfera $\left(\mathrm{pH}_{\mathrm{r}}\right)$ e no $\mathrm{pH}$ não rizosférico $\left(\mathrm{pH}_{\mathrm{nr}}\right)$ foram dependentes do $\mathrm{pH}$ inicial dos solos e da fixação biológica de $\mathrm{N}_{2}$.

2. Menores valores de $\mathrm{pH}_{\mathrm{r}}$ e $\mathrm{pH}_{\mathrm{nr}}$ ocorreram no solo arenoso.

3. O acúmulo de B, Cu, Fe, Mn e Zn na parte aérea das plantas aumentou significativamente como consequência da acidificação da rizosfera, principalmente após a nodulação.

\section{LITERATURA CITADA}

ABREU, C.A.; LOPES, A.S. \& SANTOS, G. Micronutrientes. In: In: NOVAIS, R.F.; ALVAREZ V., V.H.; BARROS, N.F.; FONTES, R.L.F.; CANTARUTTI, R.B. \& NEVES, J.C.L., eds. Fertilidade do solo. Viçosa, MG, Sociedade Brasileira de Ciência do Solo, 2007. p.645-736.

AMBROSANO, E.J.; TANAKA, R.T.; MASCARENHAS, H.A.A.; RAIJ, B.van; QUAGGIO, J.A. \& CANTARELLA, H. Leguminosas e oleaginosas. In: RAIJ, B.van; CANTARELLA, H.; QUAGGIO, J.A. \& FURLANI, A.M.C., eds. Recomendações de adubação e calagem para o Estado de São Paulo. 2.ed. Campinas, Instituto Agronômico \& Fundação - IAC, 1996. p.187-203. (Boletim Técnico, 100)

BAR-YOSEF, B.; FISHMAN, S. \& TALPAZ, H. A model of zinc movement to single roots in soils. Soil Sci. Soc. Am. J., 44:1272-1279, 1980.
BATAGLIA, O.C. Ferro. In: FERREIRA, M.E. \& CRUZ, M.C.D., eds. Micronutrientes na agricultura. Piracicaba, Potafos-CNPq, 1991.p.159-172.

BRESSAN, W.; SIQUEIRA, J.O.; VASCONCELLOS, C.A. \& PURCNO, A.A.C. Fungos micorrízicos e fósforo, no crescimento, nos teores de nutrientes e na produção de sorgo e soja consorciados. Pesq. Agropec. Bras., 36:315323, 2001.

CAVALLARO, N. \& McBRIE, M.B. Zinc and copper status and fixation by on acid soil clay: Effects of seletive dissolutions. Soil Sci. Soc. Am. J., 48:1050-1054, 1984.

CONCON, J.M. \& SOLTESS, D. Rapid microkjeldahl digestion of cereal grains and other biological materials. Anal. Biochem., 53:35-41, 1973.

CORNU, J.Y.; STAUNTON, S. \& HINSINGER, P. Copper concentration in plants and in the rhizosphere as influenced by the iron status of tomato (Lycopersicon esculentum L.). Plant Soil, 292:63-77, 2007.

GALLO, J.R.; BATAGLIA, O.C. \& MIGUEL, P.T.N. Determinação de cobre, ferro, manganês e zinco num mesmo extrato de planta, por fotometria de chama. Bragantia, 30:155-167, 1971.

GODO, G.H. \& REISENAUER, H.M. Plant effects on soil manganese availability. Soil Sci. Soc. Am. J., 44:993-995, 1980.

HINSINGER, P.; PLASSARD, C.; TANG, C. \& JAILLARD, B. Origins of root-induced $\mathrm{pH}$ changes in the rhizosphere and their responses to environmental constraints: A review. Plant Soil, 248:43-59, 2003.

JARVIS, S.C. The uptake and distribution of copper in some forage grasses as affected by nitrate-nitrogen supply in following solution culture. Ann. Bot., 84:147-157, 1981.

JONES JR., J.B. Plant tissue analysis in micronutrients. In: MORTVEDT, J.J.; COX, F.R.; SHUMAN, L.M. \& WELCH, R.M., eds. Micronutrients in agriculture. Madison, Soil Science Society of Agronomy, 1991. p.477-521.

JUNGK, A.O. Dynamics of nutrient movement at the soilroot interface. In: WAISEL, Y.; ESHEL, A. \& KAFKAFI, V., eds. Plants roots: The hidden half. New York, Marcel Dekker, 1991. p.455-482.

LUISI, M.V.V.; ROSSIELLO, R.O.P. \& FERNANDES, M.S. Acidificação do rizocilindro de milho em resposta à absorção de nutriente e sua relação com o crescimento radicular. R. Bras. Ci. Solo, 7:69-74, 1983.

MARSCHNER, H. Root-induced changes in the availability of micronutrients in the rhizosphere. In: WAISEL, Y.; ESHEL, A. \& KAFKAFI, V., eds. Plants roots: The hidden half. New York, Marcel Dekker, 1991. p.503-528.

MARSCHNER, H. Mineral nutrition of higher plants. London, Academic, 1995. 889p.

MARSCHNER, H.; ROSSENBERG-NEUHAUS, H. \& RÖMHELD, V. Rapid method for measuring changes in $\mathrm{pH}$ and reducing processes along roots of impact plants. Z. Pflanzenphysiol., 105:407-416, 1982. 
MARSCHNER, H. \& RÖMHELD, V. In vivo measurement of root-induced $\mathrm{pH}$ changes at the soil-root interface: Effect of plant species and nitrogen source. Z. Pflanzenphysiol., 111:241-251, 1983.

MARSCHNER, H. \& RÖMHELD, V. Strategies of plant for acquisition of iron. Plant Soil, 165:261-274, 1994.

MORAGHAN, J.T. \& MASCAGNI JR., H.J. Environmental and soil factors affecting micronutrient, deficiences and toxicities. In: MORTVEDT, J.J.; COX, F.R.; SHUMAN, L.M. \& WELCH, R.M., eds. Micronutrients in agriculture. Madison, Soil Science Society of Agronomy, 1991. p.371426 .

MORTVEDT, J.J. Bioavailability of micronutrients. In: SUMMER, M.E., ed. Handbook of soil science. Boca Raton, CRC Press, 1999. D71-88.

NOVAIS, R.F.; NEVES, J.C.L.; BARROS, N.F. \& SEDIYAMA, T. Deficiência de manganês em plantas de soja cultivadas em solos de cerrado. R. Bras. Ci. Solo, 13:199-204, 1989.

NUNES, F.N.; NOVAIS, R.F.; SILVA, I.R.; GEBRIM, F.O. \& SÃO JOSÉ, J.F.B. Fluxo difusivo de ferro em solos sob influência de doses de fósforo e de níveis de acidez e umidade. R. Bras. Ci. Solo, 28:423-429, 2004.

OLIVEIRA, M.F.G.; NOVAIS, R.F.; NEVES, J.C.L.; ALVES, V.M.C. \& VASCONCELLOS, C.A. Fluxo difusivo de zinco em amostras de solo influenciado por textura, íon acompanhante e pH do solo. R. Bras. Ci. Solo, 23:609-615, 1999.

OLIVEIRA, M.W.; SEDIYAMA, C.S.; NOVAIS, R.F. \& SEDIYAMA, T. Crescimento de cultivares de soja em condições de baixa disponibilidade de manganês no solo. II. Concentração e alocação do manganês. R. Ceres, 44:43$52,1997$.

OLIVEIRA JR., J.A.; MALAVOLTA, E. \& CABRAL, C.P. Efeitos do manganês sobre a soja cultivada em solo de cerrado do Triângulo Mineiro. Pesq. Agropec. Bras., 35:1629-1636, 2000 .

PEGORARO, R.F.; SILVA, I.R.; NOVAIS, R.F.; MENDONÇA, E.S.; GEBRIM, F.O. \& MOREIRA, F.F. Fluxo difusivo e biodisponibilidade de zinco, cobre, ferro e manganês nos olo: Influência da calagem, textura do solo e resíduos vegetais. R. Bras. Ci. Solo, 30:859-856, 2006.

ROBELLO, E.; GALATRO, A. \& PUNTARULO, S. Iron role in oxidative metabolism of soybean axes upon growth. Effect of iron overload. Plant Sci., 172:939-947, 2007.

RÖMHELD, V. \& MARSCHNER, H. Plant-induced $\mathrm{pH}$ changes in the rhizosphere of Fe-efficient and Fe-inefficient soybean and corn cultivars. J. Plant Nutr., 7:623-630, 1984.

RÖMHELD, V. \& MARSCHNER, H. Mechanism of iron uptake by peanut plants. I. Fe(III) reduction, chelate splitting, and release of phenolics. Plant Physiol., 71:949-954, 1983.
ROSSUM, D.van; MUYOTCHA, A.; VERSELVELD, H.W.van; STOMTHAMER, A.H. \& BOOGERD, F.C. Effects of Bradyrhizobium strain and host genotype, nodule dry weight and leaf area on groundnut (Arachis hypogaea) yield. Plant Soil, 154:279-288, 1994.

SARKAR, A.N. \& WYN, J.R.G. Effect of rhizosphere $\mathrm{pH}$ on the availability and uptake of Fe, Mn and Zn. Plant Soil, 66:361-372, 1982

SCHALLER, G. $\mathrm{pH}$ changes in the rhizosphere in relation to the pH-buffering of soils. Plant Soil, 97:439-444, 1987.

SCHUBERT, S.; SCHUBERT, E. \& MENGEL, K. Effect of low $\mathrm{pH}$ of the root medium on proton release, growth, and nutrient uptake of yield beans (Vicia fabe). Plant Nutr. Physiol. Appl., 77:443-448, 1990.

SILVA, I.R. \& MENDONÇA, E.S. Matéria orgânica do solo. In: NOVAIS, R.F.; ALVAREZ V., V.H.; BARROS, N.F.; FONTES, R.L.F.; CANTARUTTI, R.B. \& NEVES, J.C.L., eds. Fertilidade do solo. Viçosa, MG, Sociedade Brasileira de Ciência do Solo, 2007. p.275-374.

SOUZA, D.M.G.; MIRANDA, L.N. \& OLIVEIRA, S.A. Acidez do solo e sua correção. In: NOVAIS, R.F.; ALVAREZ V., V.H.; BARROS, N.F.; FONTES, R.L.F.; CANTARUTTI, R.B. \& NEVES, J.C.L., eds. Fertilidade do solo. Viçosa, MG, Sociedade Brasileira de Ciência do Solo, 2007. p.205274.

SUBRAMANIAN, K.S.; TENSHIA, V.; JAYALAKSHMI, K. \& RAMACHANDRAN, V. Biochemical changes and zinc fraction in arbuscular mycorrhizal fungus (Glomus intraradices) inoculated and uninoculated soils under differencial zinc fertilization. Appl. Soil Ecol., 43:32-39, 2009.

TAIZ, L. \& ZEIGER, E. Fisiologia vegetal. São Paulo, Artmed, 2004. 719p.

TANAKA, R.T.; MASCARENHAS, H.A.A.; MIRANDA, M.A.C.; DEGASPARI, N. \& CARMELO, Q.A.C. Ocorrência de deficiência nutricional em soja cultivada em solo de cerrado devido a incorporação superficial do calcário. Inf. Agron., 51:15-21, 1990.

TISDALE, S.L.; NELSON, W.L. \& BEATON, J.D. Soil fertility and fertilizers. New York, MacMillan, 1985. 754p.

ZAHARIEVA, T. \& RÖMHELD, V. Factors affecting cationanion uptake balance and iron acquisition in peanut grow on calcareous soils. Plant Soil, 130:81-86, 1991.

WALLACE, A. Effect of nitrogen fertilizer and nodulation on lime-induced chlorosis in soybeans. J. Plant Nutr., 5:363368,1982

WOLF, B. The determination of boron in soil extracts, plant materials, composts, manure, water and nutrients solutions. Soil Sci. Plant Nutr., 35:461-468, 1989. 